\title{
Cervical Intraepithelial Lesions in Women with Persistent Inflammatory Smear on Pap Smear: A Descriptive Cross-sectional Study
}

\author{
Junu Shrestha, 'Dilasma Gharti Magar, ${ }^{2}$ Chandani Pandey' \\ 'Department of Obstetrics and Gynaecology, Manipal Teaching Hospital, '2Department of Pathology, Manipal \\ Teaching Hospital, Pokhara, Nepal.
}

\begin{abstract}
Introduction: Persistent inflammatory smear is a benign finding on pap test but is associated with premalignant lesion of the cervix. Further evaluation is therefore necessary. This study was done to determine the prevalence of cervical intraepithelial lesions in women with persistent inflammatory smear.
\end{abstract}

Methods: This is descriptive observational study conducted in Department of Obstetrics and Gynaecology of a tertiary care centre of Nepal from 15th May 2020 to 14th May 2021 after obtaining ethical clearance from Institutional Review Board (Reference no MEMG/IRC/338/GA). Women with two consecutive pap smear reports showing inflammatory findings were enrolled. Colposcopy was performed and Modified Reid's colposcopic index was used to grade the lesions. Colposcopic guided biopsy was taken and tissue sent for histopathology for abnormal colposcopic lesions. Data analysis was done using Statistical Package for Social Sciences version 21. Point estimate at 95\% Confidence Interval was calculated along with frequency and proportion for binary data.

Results: Among 115 women, 57 (49.5\%) at 95\% Confidence Interval (40.37-58.63) had cervical intraepithelial lesions. Among them 48 (41.7\%) had low grade intraepithelial lesions and $9(7.8 \%)$ had high grade lesions on colposcopy.

Conclusions: The prevalence of cervical intraepithelial lesions in women with persistent inflammatory smear on pap was higher in our study compared to other studies.

Keywords: cervix; colposcopy; inflammation; pap smear; squamous intraepithelial lesion.

\section{INTRODUCTION}

Inflammatory smear is one of the common findings noted in pap smear. ${ }^{1-3}$ Cervical inflammation is mostly due to infections. ${ }^{3-4}$ However it may occur following chronic irritation from foreign body, trauma and chemical irritants. ${ }^{5}$ Persistent inflammatory smear is when two consecutive smears reports show inflammatory changes without atypia. Though a benign finding in pap smear, persistent inflammatory smears have been found to be associated with preneoplastic changes. ${ }^{6-9}$ Deferring further evaluation with colposcopy and guided biopsy whenever necessary may delay timely diagnosis of precancerous lesions in many.
Cervical cancer is the second most common cancer in Nepal. ${ }^{10}$ Hence, timely diagnosis and treatment of precancerous cervical lesions would help in decreasing the number of new cases of cervical cancer. Therefore, evaluation of persistent inflammatory smear with colposcopy followed by biopsy is an important secondary screening tool.

Therefore, this study was conducted with the aim to determine the prevalence of cervical intraepithelial

Correspondence: Dr. Junu Shrestha, Department of Obstetrics and Gynaecology, Manipal Teaching Hospital, Fulbari, Pokhara, Nepal. Email: junu152001@yahoo.com, Phone: +977-9856033826 
lesions in women with persistent inflammatory smear on pap smear.

\section{METHODS}

This was a descriptive cross-sectional study conducted in the outpatient department of Obstetrics and Gynaecology Department of Manipal Teaching Hospital, Pokhara, Nepal for a period of one year from 15th May 2020 to 14th May 2021. Ethical approval was taken from the Institutional Review Committee of Manipal Teaching hospital prior to conducting the study (Reference no MEMG/IRC/338/GA). Convenient sampling method was used. The study included all the women with two consecutive pap smear showing inflammatory findings without features of atypia. These women had been treated with antibiotics after the first smear showed inflammatory findings. Repeat smear was performed after six to twelve weeks of treatment and if repeat smear showed inflammatory findings, they were included in the study. Pregnant women, women on follow up after treatment for cervical cancer or premalignant lesion and women with diabetes mellitus, HIV were excluded. Women refusing to participate in the study were also excluded.

Sample size calculation was done using the formula,

$$
\begin{aligned}
\mathrm{n} & =\mathrm{Z}^{2} \times \mathrm{p} \times \mathrm{q} / \mathrm{e}^{2} \\
& =\mathrm{Z}^{2} \times \mathrm{p} \times(1-\mathrm{p}) / \mathrm{e}^{2} \\
& =1.96^{2} \times 0.16 \times(1-0.84) / 0.07^{2} \\
& =105
\end{aligned}
$$

where,

$Z=1.96$ for $95 \%$ confidence interval

$p=16 \%$, prevalence of cervical intraepithelial

neoplasia in women with persistent inflammatory

smear from previous study $16 \%{ }^{6}$

$q=1-p$

$\mathrm{e}=$ margin of error $7 \%$

Minimum sample size of 105 was calculated. However, a total of 115 participants were included in the study. The participants were informed about the nature of the study and informed consent was obtained prior to enrolment. Detailed history was taken in relation to age at marriage, menstrual history, parity and any specific gynaecological complaints. General and systemic examination was done and they were subjected for colposcopy.

Digital video colposcope (HD Inttelio) BORZE- USA, was used for this procedure. The colposcope was adjusted till the focal length was obtained for optical resolution. The cervix was visualized after moistening it with normal saline. Gross lesions, vascular details and opacity of the epithelium were looked for at this examination in low to medium magnification (4 to 10 times). Cervix was then viewed with a green filter to study vascular configuration of tissue. High magnification (10 to 20X) was used for visualization of the vascular abnormalities. Presence of any vascular changes and their nature were viewed in detail. Subsequently, the cervix was treated with freshly prepared solution of $5 \%$ acetic acid (prepared as $1 \mathrm{ml}$ acetic acid and $19 \mathrm{ml}$ of normal saline) applied with cotton swab for one minute. Any change in the cervical epithelium was noted. The intensity of the acetowhite areas, margins, borders and contour of the lesion were noted. When necessary $5 \%$ acetic acid was reapplied and cervix visualized. Finally, the cervix was treated with commercially available Lugol's iodine and inspected. Change in colour of the cervical tissue was noted after this. The Modified Reid's colposcopic index was used for the interpretation of colposcopic findings. The Reid's colposcopic index considers four colposcopic signs - margin of the lesion, color of acetowhite lesion, blood vessels, and staining with Lugol's iodine. ${ }^{11}$ Cervix which had no acetowhite areas, vascular changes or staining Mahogany brown with Lugol's iodine were considered normal. If the $\mathrm{RCl}$ score was 0 to 2, it was reported as Low Grade Intraepithelial Lesion (LSIL), 3 to 4 as overlap between LSIL and High Grade Intraepithelial Lesion (HSIL) and score 5 to 8 as HSIL. Modified RCl was used because other studies have shown good correlation of modified $\mathrm{RCl}$ with the histopathological findings. ${ }^{12,13}$

The decision to take a biopsy depended on the discretion of the person performing colposcopy. If deemed necessary, biopsies were still taken from normal and benignlooking cervixduring colposcopy.Ifabnormalities were detected in colposcopy, targeted biopsies were taken with Baby Tischler punch biopsy forceps. All the tissues biopsied were fixed in $10 \%$ formalin and sent to the pathology department for examination. The findings of histopathology were followed up and recorded.

All the information was recorded in the preformed proforma. Data entry and analysis was done using the latest Statistical Package for Social Sciences (SPSS) software version 21. Data were presented using frequencies and percentages. Point estimate at $95 \%$ Confidence Interval was calculated.

\section{RESULTS}

Colposcopic reporting was done according International Federation for Cervical Pathology and Colposcopy (IFCPC). ${ }^{14}$ On colposcopy, 57 (49.5\%) (40.37-58.63 at 95\% Confidence Interval) had abnormal colposcopic findings, mostly low grade squamous intraepithelial lesion (LSIL) and benign findings were noted in $30(26.1 \%)$ women. Colposcopy was normal in $28(24.3 \%)$ women. In six of them, biopsy was not taken (Table 1). 
Table 1. Colposcopic findings of patients with persistent inflammatory smear on Pap $(n=115)$.

\begin{tabular}{|c|c|c|}
\hline \multicolumn{2}{|c|}{ Colposcopic Findings } & n (\%) \\
\hline \multicolumn{2}{|c|}{ Normal colposcopic findings } & $28(24.3)$ \\
\hline \multirow{3}{*}{$\begin{array}{l}\text { Abnormal } \\
\text { colposcopic } \\
\text { findings }\end{array}$} & LSIL & $48(41.7)$ \\
\hline & HSIL & $9(7.8)$ \\
\hline & $\begin{array}{l}\text { Invasive } \\
\text { carcinoma }\end{array}$ & $0(0)$ \\
\hline \multirow[t]{2}{*}{$\begin{array}{l}\text { Miscellaneous } \\
\text { findings }\end{array}$} & $\begin{array}{l}\text { Immature } \\
\text { squamous } \\
\text { metaplasia }\end{array}$ & $26(22.6)$ \\
\hline & Cervicitis & $4(3.5)$ \\
\hline
\end{tabular}

On comparison of the findings of colposcopy with that of histopathology, reports of colposcopy and histopathology matched in 42 (75\%) with normal or benign findings, $32(68.1 \%)$ cases with LSIL and $3(60 \%)$ cases with HSIL. In $10(21.3 \%)$ participants with normal colposcopy, histopathology showed LSIL. Likewise, 13 (23.2\%) patients who had LSIL in colposcopy, histopathology report came as normal or benign disorders (Table 2).

\begin{tabular}{|c|c|c|c|c|c|}
\hline \multirow{2}{*}{$\begin{array}{l}\text { Abnormal } \\
\text { colposcopic } \\
\text { findings }\end{array}$} & \multicolumn{5}{|c|}{ Histopathological diagnosis } \\
\hline & $\begin{array}{l}\text { Normal/ } \\
\text { Benign }\end{array}$ & LSIL & HSIL & $N / A^{*}$ & Total \\
\hline LSIL & $13(23.2)$ & $\begin{array}{l}32 \\
(68.1)\end{array}$ & $\begin{array}{l}2 \\
(40)\end{array}$ & $\begin{array}{l}1 \\
(14.3)\end{array}$ & $48(41.7)$ \\
\hline HSIL & $1(1.8)$ & $\begin{array}{l}5 \\
(10.6)\end{array}$ & $\begin{array}{l}3 \\
(60)\end{array}$ & $0(0)$ & $9(7.8)$ \\
\hline \multicolumn{6}{|c|}{${ }^{*}$ Not available/ Not done } \\
\hline
\end{tabular}

There were 115 participants in the study. The mean age of the patients was 42 years and mean years at marriage was 22 years. Majority 80 (69.3\%) of the patients had a regular menstrual cycle. Most of them were multiparous. Per vaginal discharge was the common complaint with which patients had presented. On a gross naked eye examination, half of the patients had a healthy looking cervix and the other half had a clinically unhealthy-looking cervix (Table 3).

\begin{tabular}{|lc|}
\hline $\begin{array}{l}\text { Table } 3 . \\
\text { with persistent inflammatory smear on pap }(\mathrm{n}=115)\end{array}$ \\
\hline Mean age (years) & $42.3( \pm 9.0)$ \\
Mean age at marriage (years) & $22.1( \pm 9.2)$ \\
Clinical Characteristics & $\mathrm{n}(\%)$ \\
Menstrual cycles & \\
Regular & $80(69.6)$
\end{tabular}

\begin{tabular}{|ll|} 
Irregular & $16(13.9)$ \\
Postmenopausal & $19(16.5)$ \\
Intermenstrual bleeding & $0(0)$ \\
Parity & \\
Nulliparous & $2(1.7)$ \\
Primiparous & $8(7.0)$ \\
Multiparous & $98(85.2)$ \\
Grand multiparous & $7(6.1)$ \\
Symptoms at Presentation & \\
Routine & $14(12.1)$ \\
\hline Per vaginal discharge & $91(79.1)$ \\
Postmenopausal bleeding & $1(0.9)$ \\
Intermenstrual bleeding & $1(0.9)$ \\
Appearance of cervix on examination & \\
Healthy & $58(50.4)$ \\
Unhealthy & $57(49.6)$ \\
\hline
\end{tabular}

\section{DISCUSSION}

Inflammatory smear as a finding in pap smear is quite common but there is no consensus to the further treatment. Treatment with antibiotics is considered in some places but in some, it is left on its own considering it as a benign condition. It has been a known fact that persistent inflammation leads to increased cellular changes and metaplasia, further increasing the chance of malignant transformation. ${ }^{15}$ Hence, purpose of this study was to find the prevalence of precancerous lesions of cervix in women with persistent inflammatory smear.

The mean age of the women in this study was 42 years similar to that reported by $\mathrm{Hmid} B$ et al. and Dasari $P$ et al.8,9 Other studies reported lesser age around 30 years as mean age of patients. ${ }^{6,7,16}$ Another study reported almost $50 \%$ of women belonging to 20 to 30 years age group. ${ }^{17}$ The difference in the mean age could be due to different study settings and different screening practice in countries where studies have been conducted. Higher mean age in our study could be because women were getting screened at a later age than in other countries. The mean age of marriage was 22 years in our study similar to that of another study. ${ }^{6}$

Persistent inflammatory smear was more common in multiparous women. Same was the finding of other studies. ${ }^{7,8,16,17}$ This is expected outcome as multiparity is a known risk factor for premalignant and malignant lesions of cervix.

Vaginal discharge was the common symptom of the women with persistent inflammatory smear; same as reported by the others. ${ }^{8,16}$ However, $12 \%$ of women with repeated inflammation on pap test got tested as a routine test. 
In this study, almost $49.5 \%$ women had abnormal colposcopic findings; $41.7 \%$ had low grade lesion and $7.8 \%$ had high grade lesions. Colposcopy was normal in $24 \%$ of women. In $26.1 \%$ women colposcopic finding was that of immature squamous metaplasia and cervicitis. Similarly, in some other studies, almost 50 $\%$ of the study participants had abnormal colposcopic findings. ${ }^{6,17}$ Colposcopic findings were normal in $24 \%$ of women with persistent inflammatory smear in our study compared to 6 to $10 \%$ in studies conducted by Dasari $\mathrm{P}$ et al. and $\mathrm{Hmid} \mathrm{R}$ et al.8,9

This disparity in the normal and abnormal colposcopy could be due to different study population included in the study and could also be because of different criteria used to label colposcopy as normal or abnormal. Lack of uniformity in using standard nomenclature and classification has made comparisons difficult and unreliable.

On colposcopy, nearly $50 \%$ of women had cervical intraepithelial neoplasia. Other studies also reported abnormal colposcopy ranging from 50 to $64 \%$ women with persistent inflammatory smear ${ }^{6,8,16,17}$ Almost $42 \%$ women were diagnosed with low grade lesion and $7.8 \%$ with high grade lesion on colposcopy. Higher number of women had high grade lesion (20\%) was reported by Nahar K et al. ${ }^{17}$ However, Shanmugham $D$ et al. reported that $44 \%$ of women had low grade lesion and $18 \%$ had high grade lesion on colposcopy. ${ }^{16}$ Hence, high grade lesion on colposcopy was lower in our study compared to other studies.

In six patients, biopsy was not taken as colposcopy was normal and one patient had inadequate tissue and hence was not included in the analysis. Of 108 women who had colposcopic guided biopsy, $45 \%$ women had premalignant lesions - LSIL in $40.7 \%$ women and HSIL in $4.3 \%$ women. There were no cases of microinvasive lesion or invasive carcinoma. Chronic cervicitis was found in $43.5 \%$ women almost the same as that reported by Bhutia $\mathrm{K}$ et al. and Shanmugham D et al. ${ }^{6,16}$ The proportion of cases with premalignant lesion diagnosed on histopathology in this study was comparatively higher than in other studies. ${ }^{6-9,16-17}$ Low grade lesions were more frequent than the high grade lesions. The proportion of women with high grade lesions was $4.3 \%$ and there were no cases of invasive carcinoma in our study. Dasari $\mathrm{P}$ et al. report similar proportion of high grade lesions but there were also few cases of carcinoma in situ and invasive carcinoma. ${ }^{8}$ Other studies reported high number of cases of high grade lesions in women with persistent inflammatory smear. ${ }^{16,17}$

On analyzing the colposcopic diagnosis with histopathological diagnosis, correlation between two was present in $75 \%$ of normal/ benign findings, $68 \%$ cases of low grade lesions and $60 \%$ cases of high grade lesions in the present study. Colposcopy though normal in $21 \%$ cases, histopathology revealed that there was a low grade lesion. Likewise, 23\% cases diagnosed as LSIL and one case diagnosed as HSIL on colposcopy was found to have benign findings on histopathology. Hence, taking colposcopy guided biopsy in all cases may minimize the false negative and false positive findings in patients undergoing further investigation for persistent inflammatory smear.

This study was conducted at a single centre and did not include a diverse group of participants. Convenient sampling was used in this study. Hence the findings of the study cannot be generalized to a larger population. This was an observational study, analysis of the correlation between the findings of colposcopy and histopathology could not be done to see the sensitivity and specificity of colposcopy. Hence, a larger study involving multiple centres with analytical study design would yield more useful results.

\section{CONCLUSIONS}

The prevalence of cervical intraepithelial lesion in women with persistent inflammatory smear on the pap test was higher in our study compared to other studies. Hence, evaluation of women with persistent inflammatory smear with colposcopy and biopsy is recommended. This will help in early diagnosis and treatment of cervical precancerous lesions.

\section{ACKNOWLEDGEMENTS}

We would like to acknowledge all the participants of the study and the department of Obstetrics and Gynaecology and department of Pathology for directly or indirectly supporting the study.

\section{Conflict of Interest: None.}

\section{REFERENCES}

1. Sachan PL, Singh M, Patel ML, Sachan R. A study on cervical cancer screening using pap smear test and clinical correlation. Asia Pac J Oncol Nurs. 2018 Jul;5(3):337. [Full $\underline{\text { Text }} \mid \underline{\mathrm{DOI}}]$
2. Kulkarni PR, Rani H, Vimalambike MG, Ravishankar S Opportunistic screening for cervical cancer in a tertiary hospital in Karnataka, India. Asian Pac J Cancer Prev. 2013;14(9):5101-5. [․ubMed | Full Text | DOI] 
3. Baka S, Tsirmpa I, Chasiakou A, Tsouma I, Politi E, Gennimata V, Kouskouni E. Inflammation on the cervical papanicolaou smear: evidence for infection in asymptomatic women? Infect Dis Obstet Gynecol. 2013;2013:184302. [PubMed | Full Text $\mid \underline{\text { DOI] }}$

4. Kelly BA, Black AS. The inflammatory cervical smear: a study in general practice. Br J Gen Pract. 1990 Jun;40(335):238-40. [PubMed | Full Text]

5. Sellors JW, Sankaranarayanan R. Colposcopy and Treatment of Cervical Intraepithelial Neoplasia: A Beginners' Manual. France: International Agency for Research in Cancer; 2003. 78-83. Available from: https://screening.iarc.fr/doc/ colpochapter09.pdf [Full Text]

6. Bhutia K, Puri M, Gami N, Aggarwal K, Trivedi SS. Persistent inflammation on Pap smear: does it warrant evaluation? Indian J Cancer. 2011 Apr-Jun;48(2):220-2. [PubMed | Full $\underline{\text { Text }} \mid \underline{\text { DOI] }}$

7. Seçkin NC, Turhan NO, Ozmen S, Ersan F, Avşar F, Ustün $\mathrm{H}$. Routine colposcopic evaluation of patients with persistent inflammatory cellular changes on Pap smear. Int J Gynaecol Obstet. 1997 Oct;59(1):25-9. [PubMed | DOI]

8. Dasari P, Rajathi S, Kumar SV. Colposcopic evaluation of cervix with persistent inflammatory Pap smear: A prospective analytical study. Cytojournal. 2010 Aug 5;7:16. [PubMed | Full Text $\mid \underline{\text { DOI] }}$

9. Ben Hmid R, Mourali M, Zghal D, Mahjoub S, Naceur C, Sbai $\mathrm{N}$, et al. Apport de la colposcopie dans les frottis cervico-vaginaux inflammatoires: a propos de 140 cas [Usefulness of colposcopy in inflammatory cervico-vaginal smears: apropos of 140 cases]. Tunis Med. 2007 Jun;85(6):500-4. [PubMed]

10. International Agency for Research on Cancer, World Health Organization. The Global Cancer Observatory [Internet]. Geneva: World Health Organization; 2021 Mar [cited 2021 August 3]. Available from: https://gco.iarc.fr/today/data/ factsheets/populations/524-nepal-fact-sheets.pdf [ [ Text]
11. Ferris DG, Greenberg MD. Reid's Colposcopic Index. J Fam Pract. 1994 Jul;39(1):65-70. [PubMed | Full Text]

12. Sonali D, Kanan Y, Smita A, Suvarna D. Role of Colposcopy using Modified Reid's index in screening of cervical cancer in women with abnormal cervix on naked eye examination. J Evol Med Dent Sci. 2014 Jan;3(4):902-7. [ Full Text | DOI]

13. Durdi GS, Sherigar BY, Dalal AM, Desai BR, Malur PR. Correlation of colposcopy using Reid colposcopic index with histopathology- a prospective study. J Turk Ger Gynecol Assoc. 2009 Dec 1;10(4):205-7. [ PubMed | Full Text]

14. Bornstein J, Bentley J, Bösze P, Girardi F, Haefner H, Menton M, et al. 2011 colposcopic terminology of the International Federation for Cervical Pathology and Colposcopy. Obstet Gynecol. 2012 Jul;120(1):166-72. [PubMed | Full Text | DOI]

15. Moss SF, Blaser MJ. Mechanisms of disease: Inflammation and the origins of cancer. Nat Clin Pract Oncol. 2005 Feb;2(2):90-7; quiz 1 p following 113. [PubMed | Full Text I DOI]

16. Shanmugham D, Vijay A, Rangaswamy T. Colposcopic Evaluation of Patients with Persistent Inflammatory Pap Smear. Sch J Appl Med Sci. 2014;2:1010-3. [Full Text]

17. Nahar K, Tasnim S, Asaduzzaman MM. Colposcopic Evaluation of Cervix with Persistent Inflammatory Pap Smear. Ibrahim Cardiac Medical Journal. 2014;4(1):9-15. [Full Text $\mid \underline{\text { DOI] }}$

\section{The Author(s) 2018.}

This work is licensed under a Creative Commons Attribution 4.0 International License. The images or other third party material in this article are included in the article's Creative Commons license, unless indicated otherwise in the credit line; if the material is not included under the Creative Commons license, users will need to obtain permission from the license holder to reproduce the material. To view a copy of this license, visit http://creativecommons.org/licenses/by/4.0/ 